\title{
Die Philosophie des Als-0b in ihrer Anwendung auf den Begriff des Bewußtseins und des Unbewußten.
}

\author{
Von \\ W. Vix (Darmstadt), \\ Nervenarzt. \\ (Eingegangen am 12. November 1920.)
}

Seit einigen Jahren ist in der Philosophie eine Betrachtungsweise, wenn auch nicht von Grund auf neu eingeführt, so doch wissenschaftlich eingehend begründet worden, die von ihrem Hauptverfechter, dem Hallenser Philosophen Vaihinger, als Philosophie des Als-Ob') bezeichnet wird. - Sie geht von folgenden Grundgedanken aus:

Schon von alters her macht sich das wissenschaftliche Denken die Tatsache zunutze, daß selbst als falsch erkannte Voraussetzungen, bewußte Fiktionen, in bestimmten Fällen zu richtigen Ergebnissen führen können. Sie sind demnach prinzipiell verschieden von den Hypothesen. Diese haben die Wahrscheinlichkeit der Richtigkeit für sich und sind streng logisch aufgebaut. Freilich können sich mit dem Fortschreiten der Wissenschaft auch solche lange Zeit für richtig gehaltene Hypothesen als Fiktionen erweisen, wenn sie mit neueren Beobachtungen nicht mehr logisch vereinbar sind. Es sei nur an die Erschütterung gedacht, die die alte Äther- und Atomtheorie erfahren hat. - Weder die Natur- noch die Geisteswissenschaften sind frei von solchen Fiktionen und die am strengsten logisch aufgebaute, die Mathematik, kann sie am wenigsten entbehren.

Die Berechtigung zum Gebrauch solcher Fiktionen erhellt, abgesehen von ihrem praktischen Nutzen, ihrer ,Rechnungsergiebigkeit", aus der Auffassung Vaihingers vom Sinn des logischen Denkens: „Die logischen Prozesse sind ein Teil des kosmischen Geschehens und haben zunächst nur den Zweck, das Leben der Organismen zu erhalten und zu bereichern; sie sollen als Instrument dienen, um den organischen Wesen ihr Dasein zu vervollkommnen, sie dienen ferner als Vermittlungsglieder zwischen den Wesen." Die Vorstellungswelt ist kein Abbild der Wirklichkeit. Schon die elementaren Empfindungen sind „,bloße Maßstäbe, um die Veränderungen der Wirklichkeit zu messen“. Die Erkenntnis selbst ist gewissermaßen nur ein Nebenprodukt des logischen Denkens. Praktisch kann allerdings die Vorstellungswelt 
als Abbild der Wirklichkeit angesehen und vom Logiker in diesem Sinne benutzt werden, während der Erkenntnistheoretiker sie für fiktiv ansehen muß. Eigentliche Fiktionen in unserem strengen Sinne sind aber nicht solche erkenntnistheoretisch der Wirklichkeit widersprechende bzw. von ihr abweichende Vorstellungen, sondern die auch in sich selbst widerspruchsvollen.

Wenden wir uns nun dem Bewußtseinsbegriff zu. Als Führer wählen wir uns zunächst $W u n d t^{2}$ ), wie er zusammenfassend in seinem Werke „Sinnliche und Übersinnliche Welt" den Begriff des Bewußtseins analysiert. Er weist darauf hin, daß das Wort Bewußtsein ,eine Neuschöpfung unserer Sprache ist" und eine glückliche Utbersetzung des lateinischen Conscientia durch Christian Wolff darstellt. Hierdurch wurde der allgemeine psychologische Begriff Bewußtsein von dem moralischen Begriff Gewissen getrennt, - ein ganz besonderer Vorzug unserer Sprache. - Der Begriff des Wortes Bewußtsein selbst wird ebenfalls als verhältnismäßig neu, nämlich ,kaum weiter als auf Leibniz zurückgehend" bezeichnet. Er bezieht sich auf ,die uns unmittelbar gegenwärtigen seelischen Inhalte". Ihre wesentlichen Eigenschaften sind ihre Klarheit und die Verbindungen, in denen sie miteinander stehen. Wundt führt nun weiterhin aus, wie neben diesen Eigenschaften den Bewußtseinsinhalten keine weiteren, speziell das Bewußtsein ausmachende Eigenschaften zukommen. Namentlich verwirft er die oft gebrauchte Darstellung des Bewußtseins als einer Bühne, auf der die Vorstellungen wie Schauspieler auftauchten, kämen und gingen. Die Vorstellungen sind ja auch keine fertigen, abgeschlossenen Gebilde, die das Bewußtsein als selbständiges seelisches Vermögen bewußt macht, sie sind vielmehr wie alles Seelische ein fortwährendes Geschehen, nichts Beharrendes. Diesem seelischen Geschehen haftet eben die Eigenschaft des Bewußtseins fest an. Nur insofern sie bewußt sind, existieren die seelischen Vorgänge für uns unmittelbar überhaupt. - In gleichem Sinne spricht sich Ziehe $n^{3}$ ) aus: „Unser Bewußtsein ist nur eine Abstraktion, unsere Ideenassoziation mit ihren Empfindungen und Vorstellungen ist das Bewußtsein selbst."

Mit dem seelischen Geschehen untrennbar verbunden ist das Bestehen von Verbindungen der seelischen Elementarvorgänge untereinander. Je zahlreicher und vielfacher diese Verbindungen untereinander sind, um so klarer ist der Grad des Bewußtseins. Diese Auffassung führt zum Begriff der Aufmerksamkeit. Sie ist nach $\left.W u n d t^{4}\right)$ der ,,durch eigentümliche Gefühle charakterisierte Zustand, der die klarere Auffassung eines psychischen Inhaltes begleitete". Nur für einen kleinen Umfang von Vorstellungen besteht zu gleicher Zeit ein Maximum von aktuellen Verbindungen. Diese Anzahl von Vorstellungen, die im allgemeinen auf 6 festgesetzt wird, befindet sich im Blickpunkt 
der Aufmerksamkeit. Hier läßt sich der Vergleich mit dem Blickfeld des Auges schwer umgehen, um das Verhältnis zwischen Apperzeption (= Aufmerksamkeit) und Perzeption (= dunkler bewußter Wahrnehmung) zu schildern. Die perzipierten Vorstellungen und Gefühle befinden sich je nach ihrem Klarheitsgrad, der Zahl ihrer aktuellen Verbindungen, mehr oder weniger weit nach der Peripherie des Blickfeldes zu. Wohlbemerkt handelt es sich hier um einen Vergleich. Auch Wundt selbst kann das Wort „Bewußtsein" nicht entbehren, wenn er den Begriff auch soweit auflöst, daß er in Elemente zerfällt, in deren jedem einzelnien er als solcher nicht mehr anzutreffen ist. Erst durch ihre Verbindung untereinander wird er synthetisch wieder hergestellt. Man muß zu der Auffassung kommen, daß es sich bei Wundt im Gebrauch des Wortes Bewußtsein somit um ein Symbol, eine Abbreviatur zur Vermeidung weitschweifiger Wiederholungen und Erklärungen handelt.

Der Grad des Bewußtseins ist aber nach $W u$ undt ,, weniger von rlem Umfang der Verbindungen, als von dem Verhältnis zu bestimmten dominierenden and relativ konstanten Inhalten abhängig". Diese sind ,,jene Gruppe psychischer Inhalte, die wir mit dem Worte ,Ich" zusammenfassen, und die ,obgleich sie nicht alle inneren Erlebnisse begleitet, doch immer wieder in den Vordergrund tritt, wo wir irgend zum Handeln angeregt werden“. - Die Selbstbeobachtung bestätigt denn auch dieses Immerwiederauftauchen und Anklingen des Ich-Komplexes. Dies wird verständlich, wenn wir bedenken, daß das Ich zu den meisten Gedankengängen in enger assoziativer Verbindung steht und daß es namentlich von den mannigfaltigen körperlichen Empfindungen aus, die unsere Wahrnehmungen begleiten, beständig geweckt wird. All die vielerlei Spannungszustände in unserer Muskulatur, der mimischen, der der Sinnesorgane, der Gliedmaßen und der Zirkulations- und Atmungsorgane, die beständig durch unsere Wahrnehmungen als Reize ausgelöst werden und auch unsere Gedankengänge begleiten, sind eng verbunden mit der Ich-Vorstellung; ganz besonders aber unser Handeln. Auf dem Vorwiegen dieser Muskelempfindungen beruhen die Storchschen Anschauungen von der Myopsyche im Gegensatz zur Pathopsyche, den reinen Sinnesempfindungen. Auf der Verarbeitung dieser Sinnesempfindungen zusammen mit den Muskelempfindungen beruht zunächst der Aufbau unseres Weltbildes. Die Eigenschaften, die wir den Dingen zuschreiben, sind um so objektiver, je mehr dabei unsere Muskeltätigkeit bei der Wahrnehmung mitwirkt und mitempfunden wird. Somit ist die objektivste die Tastwahrnehmung. Eingehend setzt Storch dann noch die Rolle auseinander, die die Myopsyche beim Zustandekommen der Zeit- und Raumvorstellung spielt. Somit begegnen wir demnach beständig mit Muskelempfindungen, also körperlichen, zusammenhängenden Vor- 
stellungen und Wahrnehmungen, womit das beständige Anklingen des Ich-Komplexes direkt verbunden ist. - In ähnlichen Gedankengängen bezüglich der Muskeltätigkeit bewegt sich neuerdings Ruckhaber ${ }^{6}$ ), der speziell auf die Bedeutung der Augenmuskeln bei den Denkvorgängen hinweist. Einer ähnlichen Beobachtung werden wir später auch bei einem anderen Autor gedenken.

Der Ich-Komplex ist auch für Ebbinghaus s) ,bei weitem die herrschendste Vorstellung des Seelenlebens", die „,nur in Fällen starker Inanspruchnahme der Seele“, bei „,Selbstvergessenheit, Versunkenheit, Verzücktheit der Seele" fehlt. Seele ist ihm alles bewußte seelische Geschehen. Der im Grunde genommen wechselnde Ich-Komplex ist aber nur ein Teil davon, der sich von den die Außenwelt ausmachenden Vorstellungskomplexen nicht einmal scharf abtrennen läßt. Auch für Ebbinghaus läßt sich ans der Einheit des seelischen Geschehens, die in viele Einzelheiten zerfällt, diese Einheit ebensowenig als Bewußtsein an sich absondern ,,wie der organische Leib von seinen Teilen". Diese Einheit entspräche unserem rätselhaften Bewußtseinsbegriff.

Diese Ausführungen enthalten ungefähr das Wesentliche, was die normale Psychologie vom Begriff des Bewußtseins lehrt. - Wenn es auch für deren Zwecke ausreichen mag, so bleiben doch viele Beobachtungen aus der Psychopathologie und selbst aus dem Alltagsleben, soweit man noch nicht von Krankhaftem, sondern höchstens Ungewöhnlichem sprechen kann, unberücksichtigt. So spricht sich denn auch Ble ule ${ }^{8}$ ) in seinem Lehrbuch der Psychiatrie unumwunden dahin aus, daß man mit der Herbartschen Erklärung, das Bewußtsein sei die Summe aller wirklichen oder gleichzeitig gegenwärtigen Vorstellungen, in der Psychopathologie nichts anfangen könne. Unterscheidungen zwischen bewußten und unbewußten psychischen Vorgängen seien nicht zu entbehren. Er vertritt den Standpunkt, daß es unbewußt psychische Vorgänge gebe, die sich von den bewußten nur durch den Mangel der Bewußtseinsqualität unterschieden. Jede beliebige Funktion könne sowohl bewußt als auch unbewußt ablaufen. Fine Vorstellung von dem Verhältnis zwischen bewußt und unbewußt könne man sich am besten machen, wenn man annehme, daß eine Funktion dann bewußt werde, wenn sie direkt mit dem IchKomplex assoziativ verbunden wird. Ist sie es nicht, so läuft sie unbewußt ab. Mit dieser Auffassung, die sich schon an Fre ud ${ }^{9}$ ) anlehnt, sind wir bei diesem zur Zeit populärsten Verfechter des Begriffes des Unbewußten in der Psychologie und Psychopathologie angelangt. Seine Anschauungen entsprechen den nach Bleuler zitierten. Er stellt sie aber folgendermaßen dar: In der menschlichen Psyche befinden sich zwei gesonderte Gebiete, das des Bewußten und das des 
Unbewußten. Zwischen beiden waltet eine ebenfalls unbewußte Tätigkeit, die Zensur, die verhindert, daß gewisse Inhalte des Unbewußten, wenigstens in unveränderter Gestalt, in das Bewußtsein gelangen. Wir treffen hier Anschauungen, die den Wundtschen und denen der Vertreter der ersten Gruppe gerade entgegengesetzt sind.

Sehr bemerkenswert sind die Ausführungen über ,,die Phasen des Bewußtseinsaktes" des Freudanhängers Hollos ${ }^{10}$ ). - Er geht aus von dessen Auffassung, daß das Bewußtsein ,ein Sinnesorgan für die Wahrnehmungen der objektiven Reize und eines Teiles der Denkvorgänge" sei. (Freud, Traumdeutung, 4. Aufl., S. 447.) Dieses „Sinnesorgan“ hat nach Hollos gleichsam zwei Sinnesoberflächen, deren eine den Wahrnehmungen, deren andere den vorbewußten Denkvorgängen zugewandt ist. „Die Helligkeit des Bewußtseins setzt eine Fähigkeit zur Besetzung beider Wahrnehmungsflächen voraus." Bei ausschließlicher Besetzung des einen Wahrnehmungsaktes wird subjektiv das Selbstbewußtsein entsprechend verdunkelt. Das volle Selbstbewußtsein setzt ein Optimum des Verhältnisses voraus. Der Anfang und das Ende einer Assoziationsreihe stehen diesem Optimum am nächsten, während die Zwischenglieder mehr oder weniger unbewußt bleiben können. Hollos benutzt offenbar als.Kriterium des erhaltenen Bewußtseins das Erinnerungsvermögen für die psychischen Inhalte der betreffenden Zeiten. Hierauf wird später bei der Besprechung der Methode der Untersuchung des Bewußtseins nochmals zurückgekommen werden müssen.

Bei längerem Assoziieren fehlt nach Hollos die äußere Wahrnehmung. Die ganze psychische Energie ist gleichsam gebunden und ist ohne Verhältnis zum Ich, das augenblicklich eigentlich nicht existiert. In diesem Falle, der Versunkenheit, fehlt das Bewußtsein.

Die unbewußte Zielvorstellung des Wachseinwollens begünstigt das Immerwiedereintreten des Bewußtseinszustandes zuungunsten des Zustandes des unbewußten Assoziierens, ebenso wie umgekehrt die Zielvorstellung des Einschlafenwollens das Einschlafen begünstigt. Diese Auffassung ist dem Begriff der Zensur Fre uds nahe verwandt und erinnert auch an die Zielvorstellung und Konstellation anderer Psychologen. - Beispiele für Bewußtseinsstörungen durch Vorwiegen einer seiner beiden Bewußtseinsphasen sind nach Hollos Tagträumerei, katatoner Stupor und tiefe Depression beim Versunkensein in die Assoziationsreihe einerseits und die Hypermetamorphose in der Manie beim Vorherrschen der Wahrnehmungsreihe andererseits. Im ersteren Falle ist der Blick in's Unendliche gerichtet, also gegen optische Reize abgeschlossen, im zweiten wird er lebhaft von einem Gegenstand dem anderen zugewandt. Wir finden somit hier Anklänge an die Storchschen Anschauungen von der Myopsyche. 
Dem Unbewußten wird von der Freudschen Richtung ebenso wie dem Bewußtsein, ja vielleicht in noch höherem Grade, Aktivität zu geschrieben, es wird personifiziert: Das Unbewußte zieht gewisse Inhalte an sich.

In die Abfassung dieser Arbeit fällt die Auseinandersetzung zwischen Bleuler und Kretschmer $\left.\left.{ }^{11}\right)^{12}\right)^{\mathbf{1 3}}$ ) über den Begriff des Unbewußten. Sie zeigt, wie nützlich es ist, die Frage auch vom philosophischen Standpunkte aus zu behandeln.

In seiner Erwiderung gegenüber den Angriffen Bleulers stellt Kretschmer fest, daß er in allem Sachlichen im wesentlichen mit Bleuler übereinstimme, im Begrifflichen bestünde nur eine ernsthafte Differenz, sie betreffe die Beziehung der Begriffe Seele und Bewußtsein. Kretschmer neigt hierbei offenbar mehr zu der Ziehenschen Auffassung, die Bewußtsein und Seele gleichstellt. Er ist der Ansicht, da $\$$ vieles, was man im bequemen praktischen Tagesgebrauch als das Unbewußte bezeichnet, trotzdem ruhig unter dem Begriff Seele bleiben könne, weil es bei scharfem Zusehen gar nicht absolut unbewußt, sondern nur dunkel und zeitweise minderbewußt sei. Er gibt auch zu, daß man fehlende Glieder in der psychischen Kausalkette als etwas Psychisches denken solle. Dann bezeichnet er den Begriff des Unbewußten als bunt, er habe innere Reibungen, könne aber, weil er handlich und praktisch sei, doch verwandt werden. Diese Auffassung entspricht nun durchaus der Vaihingerschen Als-Ob-Betrachtung. Die Erkenntnis wird durch Einführung des Bewußtseinbegriffes vorerst direkt nicht gefördert, aber es ist wertvoll, eine Ordnung und logische Anschaulichkeit, den Schein der Begreiflichkeit der Phänomene, in das Tatsachenmaterial zu bringen. Von ihm gilt was Flügel*) über die Fiktion des Allgemeinbegriffes sagt: „Die logischen Begriffe sind in Wirklichkeit niemals fertige, abgeschlossene Vorstellungen, sondern mehr Forderungen an das Denken, logische Ideale, welche, je höher die Abstraktion getrieben wird, dem Denken um so mehr Zwang auferlegen." Vielleicht will aber auch Bleuler das Gleiche sagen, wenn er die Lehre vom Unbewußten (S. 81 l. c.) eine begriffliche Abgrenzung nennt, die ihre sehr guten theoretischen und praktischen Gründe hat. Da praktische Gründe Zweckmäßigkeiten sind, so begegnen wir auch hier wieder dem Gedanken der Fiktion. Freilich scheint das Bleuler nicht in dem unumwundenen Sinne zuzugeben wie Kretschmer. Es gibt eben, wie Vaihinger gezeigt hat, verschiedenerlei Arten von Fiktionen. Nicht allein darüber ist ein Streit möglich, ob überhaupt eine Hypothese oder eine Fiktion vorliegt, - für Goethe war die Urform der Pflanze eine Hypothese, für Schiller eine Fiktion, - sondern auch darüber, um was für eine Art von Fiktion es sich handelt. Es

*) Zitiert nach Vaihinger, Phil. d. Als-Ob. 
kann etwa bei dem einen Autor eine rein sprachliche Zusammenfassung von Phänomenen, eine „Nominalfiktion“, vorliegen, während der andere aus den Phänomenen eine besondere Qualität oder ein seelisches Vermögen, das Unbewußte, aber auch mit der bewußten Absicht eine Fiktion zu bilden abstrahiert.

Zur Auseinandersetzung Bleuler-Kretschmer hat auch Bum$\mathrm{ke}^{14}$ ) das Wort ergriffen. Für ihn entsteht das Problem mit der Annahme, daß ,die bewußt psychische Reihe durch unbewußte Glieder nicht nur unterbrochen, sondern verändert, beeinflußt und weitergeführt wird". Dieser Annahme aber schließt er sich nicht an. Zunächst besteht er überhaupt nicht darauf, mit Bleuler ,die psychische Kausalkette vollständig zu haben“", und läßt cerebrale, nicht psychische Prozesse als Z Zwischenglieder gelten. Er weist dabei darauf hin, daß die Frage, ob cerebral oder psychisch für diese unbewußten Vorgänge untergeordnet sei. Weiterhin bestreitet er aber, daß die meisten sog. unbewußten psychischen Vorgänge, das unbewußte Denken und Fühlen, wirklich ganz unbewußt seien. Sie seien eben eigentlich doch bewußt oder nur dunkler bewußt. Die psychologische Analyse, namentlich der Gefühle, sei so schwer, daß vieles sich kaum oder gar nicht in Worte fassen lasse, und deshalb für viele Menschen den Charakter des Unbewußten habe. „Der Laie nennt eben bewußt, was im Bewußtsein nicht vom Wort getragen wird, und sein Unterbewußtsein fällt im wesentlichen mit dem zusammen, was wir als Gefühlspsychologie bezeichnen." Bumke erblickt gerade hierin einen neuen wichtigen Gesichtspunkt. - Bumke wendet sich mit Schumann gegen die „Rationalisierung des Unbewußten“. Die Lehre vom Unterbewußten ist ihm eine jetzt überwundene Phase, in der er keinen Nutzen mehr erblickt.

Bumke läßt somit den Begriff des Unbewußten auch als Fiktion, da jetzt abgetan, nicht mehr gelten. Für das Bewußtsein nimmt er aber doch „Stufen" an und behält das Bild vom Blickfeld des Bewußtseins bei. Die Begriffe psychisch und bewußt scheinen sich bei ihm völlig zu decken. An Stelle von ,unbewußt“ träte dann vielleicht "dunkler bewußt".

Als Gegner des Begriffes des Unbewußten erweist sich auch Le win ${ }^{15}$ ): „Der Begriff des Unbewußten ist unwissenschaftlich, da keinerlei positive Kriterien angebbar sind, die ihn vom Bewußten unterscheiden." Daßß auch für das Bewußte solche positive Kriterien fehlen, sich wenigitens nicht in Worte fassen lassen, ist in unserer Arbeit schon gezeigt worden. Lewin will das Bewußtsein nicht als vom seelischen Geschehen trennbar aufgefaßt haben. Nicht einmal im Sinne einer Fiktion sei diese Ansicht (Abtrennbarkeit des Bewußtseins vom seelischen Geschehen) brauchbar, ,weil sie. die Tatsachen nicht für, sondern 
gegen sich hat". - Dieser letztere Einwand entspricht nun aber nicht dem Wesen der Vaihingerschen Fiktion: sie kann sogar Tatsachen gegen sich haben, wenn sie nur sonst brauchbar ist. Nach Lew in darf man ,den Begriff des Bewußtseins nicht indentifizieren mit der Fähigkeit des Subjekts, sich eines Vorganges bewußt zu sein. Aus der Kompliziertheit und Fülle des jeweiligen Erlebens steht dem Subjekt immer nur ein bestimmter Ausschnitt zur Verfügung, ist bewußt; wenn ihm aber irgendwelche Vorgänge nicht zum Bewußtsein kommen, so ist es noch kein Beweis dafür, daß sie sich nicht doch im Bewußtsein abgespielt haben." Diese Stelle ist etwas schwierig. Es ist kein rechter Unterschied zu erkennen zwischen dem ,sich eines Vorganges bewußt sein" und dem zur Verfügung stehen eines bestimmten Ausschnittes aus einem Erlebnis, wenn man nicht das ganze Erlebnis als dunkel, den Ausschnitt als klarer bewußt auffassen will, wobei man an den Vergleich mit dem Blickfeld denken muß, „Zur Verfügung stehen" kann auch so viel bedeuten als leicht erinnerbar. Nicht zum Bewußtsein kommende Vorgänge, die sich aber doch im Bewußtsein abgespielt haben, kann man sich aber doch kaum anders als ,,vergessen" oder ,,verdrängt" vorstellen und muß schon dagegen ankämpfen, daß sich einem dann nicht der so handliche Begriff des Unbewußten aufdrängt. Für Lewin ist das Minderbewußte kein Quantitätsunterschied, sondern ein qualitativer. Das leuchtet ein, aber am besten ist es doch $\mathrm{zu}$ charakterisieren, wenn man die quantitative Bezeichnung einstweilen wenigstens beibehält: wenn Lew in , das Unklare" sagt, so tut er schließlich doch das Gleiche, indem er einen negativen, also quantitativen Ausdruck gebraucht. Das Minderbewußte kann eben doch nur am Bewußten gemessen werden.

Im Gesamterlebnis setzt Lew in an Stelle der Kausalen die Erlebniszusammenhänge, die nur einfühlbar sind. Er findet in den Erlebniszusammenhängen nur ,,außerbewußte Bedingungen, Begleit- und Folgeerscheinungen", aber keine Kausalglieder und polemisiert gegen Bleulers Suchen nach kausalen Zusammenhängen.

In der Diskussion setzt sich Liepmann dafür ein, daß man, um Umständlichkeiten in der Darstellung seelischer Vorgänge zu vermeiden, den ,Hilfsbegriff des Unbewußten" beibehalten solle. Er hält demnach diese Fiktion für wertvoll.

In seinem Vortrag zur ,Psychologie der Besonnenheit" sagt Schweninger ${ }^{16}$ ): ,Erkenntnis vom lebendigen seelischen Geschehen ist ohne alle Theoretisierung möglich und notwendig durch einfühlendes Verstehen und synthetische Behandlung der ganzen innerlich bewegten Lebendigkeit." Er trennt von dem aktuellen ein virtuelles Bewußtsein ,,als dauernde konstante Strömungen gleichsam in einer anderen seelischen Sichicht, im seelischen Hintergrund". Das Wörtchen ,gleich- 
sam" macht auch hier diese Auffassung oder doch den Vergleich zu einer Fiktion. Der ",seelische Hintergrund" dürfte sich doch mit dem Un- oder Unterbewußten der meisten Autoren decken.

Selbst da, wo das Bestreben besteht, Theoretisierungen auszuschalten, begegnen wir also Fiktionen. Unsere Logik und Sprache sind eben so durchtränkt von ihnen, daß wir ohne sie nicht in der Lage sind, weder uns selbst, noch anderen etwas klarzumachen. Diese Tatsache führt aber dann zu Mißverständnissen und Aneinandervorbeireden, wenn die Fiktionen in der Diskussion nicht als solche erkannt werden.

Aus diesem Grund scheint mir die Einführung nicht nur des Begriffes, der ja offenbar schon länger vorhanden ist, sondern besonders auch der Bezeichnung Fiktion in die Psychiatrie fruchtbar zu sein. Wir sind ja alle gewohnt, täglich mit fiktiven Begriffen bewußt zu arbeiten: die freie Willensbestimmung in der Gutachtertätigkeit z. B. ist für uns ja nur als Fiktion annehmbar.

Betrachten wir uns nun einmal die Wege, auf denen das Bewußtsein untersucht werden kann.

Unmittelbare Beobachtungen können nur unsere Selbstbeobachtungen als eigenes Erlebnis sein. In anderen Individuen läßt sich das Bewußtsein nur aus indirekten Anzeichen vermuten. Wer also in den Tieren, wie Descartes, nur Automaten erblicken wollte, würde schwer zu widerlegen sein. Aber auch den Ergebnissen der Selbstbeobachtung stehen theoretische Bedenken entgegen. Untersuchungssubjekt und -objekt sind identisch. Der gleiche Akt soll zu gleicher Zeit sich selbst beobachten und von sich selbst beobachtet werden. Darin liegt neben anderen Schwierigkeiten die Notwen]igkeit, daß das Bewußtsein nur als sich selbst beobachtendes, also in einem ganz speziellen Fall, beobachtet werden kann.

Der natürliche, durch diese Obervorstellung unbeeinflußte Gedankenablauf kann nicht beobachtet werden. Es ist dies ein von den Philosophen gemachter Einwand. Die Selbstbeobachtung wird sich also meist auf die unmittelbar vorhergegangenen Vorgänge, soweit sie mit oder ohne besondere Absicht gemerkt worden sind, erstrecken. Von diesen haften aber dann nur die Inhalte in der Erinnerung. Das Gefühl des Bewußtseins wird nicht analysiert, sondern nur aus der Lebhaftigkeit der Erinnerung geschlossen. Ob von dem bewußt wahrgenommenen seelischen Inhalte tatsächlich ein Bewußtseinsgefühl getrennt werden kann, ist sehr zweifelhaft, theoretisch kann man aber von einem Gefühl des Wachseins des bewußten Seins sprechen. Wundt spricht auch von einem Gefühl der Aufmerksamkeit, das doch dem BewuBtseinsgefühl sehr ähnlich ist. Jeder Versuch, es zu analysieren, stößt dann aber wieder auf die psychischen Inhalte, womit sich die Analyse erschöpft. In diesem Zusammenhang erscheint es nicht mehr 
erstaunlich, daß das Wort und damit der Begriff Bewußtsein erst so spät auftauchte und den fremden Sprachen noch fehlt. Es fällt schon rein sprachlich auf, daß wir dem Bewußtsein kein „Unbewußtsein" sondern das substantivierte Adjektiv ,d as Un bew u Bte" gegenüberstellen müssen. Treffender wäre aber in diesem Zusammenhang noch umgekehrt statt Bewußtsein das Bewußte zu sagen, um eine bestimmte Eigenschaft psychischer Inhalte und Vorgänge zu bezeichnen. Für Freud jedoch handelt es sich, wie gesagt, bildlich um zwei getrennte Gebiete, in die die Inhalte eintreten, also um etwas Selbständiges.

Freud kommt zu seinen Ergebnissen nicht in erster Linie durch Selbstbeobachtung, sondern indem er von der Untersuchung der psychischen Inhalte ausgeht, und zwar von ihren Äußerungen in anderen Personen, die er als Arzt beobachtet. Wenn wir es hier zum Teil mit pathologischen Erscheinungen zu tun haben, so dürfen wir doch nicht annehmen, daß nun die in Frage kommenden psychologischen Grundtatsachen deshalb prinzipiell vom Normalen verschieden seien. Vor diesem Fehler bewahrt schon die Unmöglichkeit der scharfen Abgrenzung des Gesunden gegenüber dem Kranken. Freud begegnet nun bei diesen Untersuchungen den Folgen von psychischen Geschehnissen, die nicht bewußt vor sich gegangen sind. Ihr Nachweis gelingt dadurch, daß er sie bewußt macht, d. h. ins Gedächtnis zurückruft. Für viele kann er somit doch nachweisen, daß sie früher wẹnigstens einmal bewußt vor sich gegangen und nur verdrängt, das heißt absichtlich, wenn auch mit unbewußter oder sich selbst nicht eingestandener Absicht, vergessen wurden. Wir begegnen hier wieder dem Kriterium des Erinnerns, um bewußt und unbewußt nachträglich unterscheiden zu können, - zweifellos einem nicht sehr zuverlässigen Merkmal. Freud ist aber auch bestrebt, psychische Vorgänge wachzurufen, die, vielleicht abgesehen von ihren Ausgangsgliedern, ganz im Unbewußten sich abspielen und nur gelegentlich durch Auftauchen affektiver Störungen im Bewußtsein oder sonst unverständlicher Handlungen ihre Existenz verraten. Jedenfalls ist die Frage zu erwägen, ob die anscheinend unbewußten Vorgänge nicht nur unmittelbar nach ihrem Ablauf vergessen oder verdrängt worden seien, etwa wie die Träume ja auch außerordentlich schnell vergessen werden. Dann müßten allerdings auch die Freudschen Symbolisierungen, Verdichtungen usw. ursprünglich einmal unbewußt vor sich gegangen sein, was jedoch wenig wahrscheinlich ist. - Für die Existenz wirklich unbewußten seelischen Geschehens spricht aber auch in der normalen Psychologie das Vorkommen von Einfällen und Intuitionen, deren assoziative Verknüpfung unbekannt bleibt oder nur retrogad vermutet werden kann. Hierher gehören z. B. auch zutreffende und selbst geistreiche 
Einwände in der Unterhaltung, die ohne tberlegung erfolgen. Eine scharfe Abtrennung von den automatischen Handlungen, die als komplizierte eingeübte Reflexe aufgefaßt werden, ist gegenüber psychischen Äußerungen nicht immer möglich. - Es kommt offenbar vor, daß ein zur Zeit des Geschehens unbewußter psychischer Vorgang hinterher spontan erinnert wird. Es erfolgt etwa eine Wahrnehmung, die zunächst gar keinen Eindruck macht, nicht bewußt wird. Wird sie nun später assoziativ geweckt, so steht sie auf einmal in der Erinnerung, aber oft als subjektiv ganz neue Erkenntnis klar vor uns, mußte also dem Gedächtnismaterial doch einverleibt worden sein. Das Vorkommen solcher Fälle ist nicht zu bezweifeln. Viele interessante Beispiele dafür bringt Lehmann ${ }^{17}$ ) in seinem ,Aberglauben und Zauberei“, die fälschlich als Hellsehen gedeutet wurden. Hierher gehören auch die Beispiele aus der Psychopathologie des Alltagslebens von Freud. Solche unbewußte Wahrnehmungen sind also ohne Beziehung zum Ich-Komplex und mit an Zahl sehr geringem Eingehen assoziativer Verknüpfungen erfolgt. Hätten letztere aber ganz gefehlt, so hätte auch ihre Erinnerungsfähigkeit fehlen müssen. Zur Zeit der Wahrnehmung fehlte dafür aber das Bewußtsein mehr oder weniger. Solche Fälle legen doch die Auffassung nahe, daß es Bewußtseinsgrade geben müsse, die allmählich über ein nur durch Erinnerung bewußt zu machendes, ursprünglich unbewußt erfolgendes Geschehen, sich in das absolut Unbewußte, das überhaupt nicht mehr aufgefaßt, deshalb dem Gedächtnismaterial auch nicht einverleibt werden kann, also den Nullpunkt fortsetzte. Es lassen sich sogar normalerweise rhythmische Schwankungen des Bewußtseinsgrades feststellen. Mit der Abnahme der assoziativen Verknüpfungen einer Wahrnehmung nimmt natürlich auch ihre Erinnerungsfähigkeit ab.

Die Verteidiger des Begriffes des Unbewußten treffen, wie gesagt, es auch im normalen psychischen Geschehen an, ja viele Erscheinungen des normalen psychischen Geschehens werden ihnen nur durch die Annahme unbewußter $Z$ wischenglieder verständlich. Vielmehr gilt dies aber noch von den abnormen, krankhaftei Zuständen, in denen sich Folgen unbewußter Ideenkomplexe geltend machen.

Wenn die assoziativen Verbindungen und das Anklingen des IchKomplexes das Wesen des Bewußtseins ausmachen sollen, so müssen sich Störungen der Persönlichkeitsvorstellung auch in Bewußtseinsstörungen äußern. Tatsächlich ist dies auch in den Fällen von Spaltung der Persönlichkeit, die mit Dämmerzuständen einherzugehen pflegt, der Fall. Wie weit der schizophrene Zerfall der Persönlichkeit mit Bewußtseinsstörungen verbunden ist, läßt sich bei der mangelhaften Auskunft der Patienten über ihre Zustände und der Schwierigkeit sich einzufühlen schwer beurteilen. Man muß sich natürlich hüten, hier das 
Persönlichkeitsbewußtsein, also den speziellen Inhalt der bewußten Vorstellungen, die den Ich-Komplex ausmachen, mit dem Begriff des Bewulitseins überhaupt zu verwechseln.

Dem Aufhören aller Assoziationen im Schlaf und der tiefen Hypnose entspricht eine Aufhebung des Bewußtseins. Im Traum und in der hypnotischen Suggestion sind die Assoziationen nicht frei, die Wahrnehmung und die Kritik der tatsächlichen Situation fehlen so gut wie ganz, die Vorstellung von der eigenen Person kann der Realität entsprechen, aber auch im Sinn des Traumerlebnisses oder der Suggestion abgeändert sein. Der Grad der Erinnerungsfähigkeit steht wahrscheinlich in einem gewissen Verhältnis zu dem Grade des Bewußtseins in diesen Zuständen.

$\mathrm{Ob}$ es Bewußtseinsgrade gibt oder nicht, auch darüber sind die Ansichten geteilt. Wenn Bleuler ${ }^{18}$ ) das Bewußtsein als die nicht beschreibbare Eigenschaft der psychischen Vorgänge bezeichnet, die das empfindende Wesen vom Automaten unterscheidet, so ist somit für diese Frage noch nichts vorweggenommen. Die Alternative zwischen vorhandenem oder ganz fehlendem Bewußtsein scheint mir doch den tatsächlichen Verhältnissen nicht zu entsprechen. Schon der Gebrauch des Wortes Bewußtseinstrübung läßt auf die weitere Verbreitung der Annahme graduell geringerer Bewußtseinszustände schließen, auch abgesehen von dem Umfang der Inhalte. Es ist auch nicht abzusehen, weshalb die ,nichtbeschreibbare Eigenschaft" Ble ulers, die das Bewußtsein ausmacht, nicht in verschiedenen Graden angetroffen werden kann.

Man kann den Bewußtseinsbegriff und seine Kehrseite, das Unbewußte, nicht gut behandeln ohne auch auf E. v. Hartman $n^{19}$ ) hinzuweisen. In seiner Philosophie des Unbewußten widmet er dem Unbewußten im menschlichen Denken eine eingehende Betrachtung.

Er zeigt, daß schon bei einfachen Willenshandlungen zwischen die bewußte Absicht und die ausgeführte Muskelbewegung unbewußte psychische Vorgänge eingeschaltet sind. In welcher Weise aus der Klaviatur der motorischen Ganglienzellen die Auswahl der zu den betreffenden Muskeln gehörigen erfolgt, ist uns ganz unbekannt, trotzdem erfolgt sie in feiner Weise. Mit der fortschreitenden Utbung entzieht sich die Ausführung überhaupt immer mehr dem Bewußtsein. Man denke nur an den Violinvirtuosen: die Einübung erfolgt noch unter genauem Aufmerken auf die Noten und den Fingersatz, das Auswendigspiel nur noch unter Leitung des Gehörs, vielleicht noch ab und zu unter Anklingen optischer Notenerinnerungsbilder, das freie Phantasieren weist eine noch größere Lücke zwischen bewußten Intentionen und bewußter Ausführung auf. - Ebenso erfolgt die Auswahl aus dem Gedächtnismaterial unbewußt. Wir können zwar die Zielvorstellung bewußt festhalten, die auftauchenden Erinnerungen bewußt aufgreifen 
oder verwerfen, aber gerade das Auftauchenlassen können wir nicht bewußt vornehmen, nur dafür günstige Bedingungen schaffen, indem wir bei assoziativ verwandten Vorstellungen, die uns schon bewußt sind, verweilen und die Einfälle abwarten.

Könnte man bei der Auswahl der zur Muskelbewegung erforderlichen Nervenzellen diesen Vorgang noch mehr als physiologisch auffassen, so muß doch ganz sicher das Sichbesinnen als etwas Psychisches bezeichnet werden. Freilich gibt es keinen Gegenbeweis gegenüber dem Einwand, die sogenannten unbewußten und vorbewußten psychischen Vorgänge seien nur materielle gehirnphysiologische Vorgänge, die die materiellen Äquivalente und Vorbedingungen für die später wieder einsetzenden Bewußtseinsvorgänge schafften, also eine Unterbrechung des hypothetischen psychophysischen Parallelismus in dem Sinne, daß streckenweise die psychische Parallele fehlte. Der Unterschied in den Auffassungen wäre der, ob man vom Psychischen oder vom Physischen aus das Bewußtsein vermißt, sich also, ,im Unbewußten befindet". Diese Frage wird in der Erörterung Kretschmer-Bleuler-Kretschmer von beiden als unlösbar und deshalb unwichtig bezeichnet. v. Hartmann faßt den Begriff des Unbewußten viel weiter, als für unsere vorliegenden Betrachtungen in Frage kommt. Es ist für ihn schließlich etwas Teleologisches, ein mystisches kosmisches Prinzip. Erwähnt werden muß aber noch seine Feststellung des Unbewußten in den Instinkthandlungen der Tiere.

Es entspricht den naturwissenschaftlich monistisch orientierten Anschauungen, für das psychische Geschehen materielle Vorgänge im Gehirn ursächlich verantwortlich zu machen, und all unsere exakten Erfahrungen sprechen in diesem Sinn. Recht schwierig wird die Durchführung dieses Gedankens aber, wenn wir primitiven Nervensystemen bei hohen geistigen Leistungen begegnen. Die Organisation von Insektenstaaten, - man denke an Bienen, Ameisen, Termiten usw., - stellt uns vor die schwierigsten Fragen in dieser Beziehung. Man kann sich nicht denken, daß das Insekt mit seinen paar Ganglienknoten überhaupt eine bewußte Vorstellung von seiner Staatenorganisation und seinen Aufgaben darin habe: sehr schwer ist es zu verstehen, wo die materiellen Äquivalente seiner wenn auch unbewußten Antriebe sich abspielen, die für das einfache Nervensystem noch allzu kompliziert erscheinen: eine weitere Erschwerung der schon beim Menschen unlösbaren Frage der Beziehungen zwischen psychischen und physiologischen, ja in gewissem Sinne sogar morphologischen Verhältnissen.

Die psychische Leistung des Einzeltieres erscheint freilich geringer, wenn wir bedenken, daß unserer Betrachtung gewissermaßen nur ein Querschnitt oder eine Momentaufnahme aus einem auf unendlich viele Generationen sich erstreckenden, langen Fluß psychischen Geschehens 
zugänglich ist, wobei das Individuum seine Rolle erbt und mit höchstens minimalen Zutaten im Sinn einer Anpassung an sich ändernde äußere Lebensbedingungen weiterspielt, um sie seinerseits ebenso weiterzuvererben. Die selbständige Leistung des Einzeltieres erscheint somit wesentlich geringer, das Rätsel aber nicht kleiner. Das wirkende Moment wird aus dem individuellen Nervensystem teilweise heraus verlegt, in die Summe aller Vorfahren oder noch darüber hinaus: wir treffen auf das Unbewußte im Sinne v. Hartma nns. In diesem Sinne müssen wir allerdings auch in der menschlichen Psyche das Walten eines unerklärlichen Unbewußten anerkennen, das mit dem Prinzip der Entwicklung überhaupt identisch ist. Kann man auch dieses die ganze Welt durchdringende Prinzip beim Menschen in das Gehirn lokalisieren?

- Jedenfalls eine schwer zu beantwortende Frage.

Es liegt nicht in der Absicht dieser Arbeit, die sich hier aufdrängenden Gedanken weiterzuspinnen. Es soll nur gezeigt werden, wie der Begriff des Unbewußten, isoliert auf die Denkvorgänge beim Menschen angewandt, zwar abgerundete und als Erklärung für viele psychische Erscheinungen sehr brauchbare Vorstellungen liefert, aber allgemeiner gefaßt seine Begrenzung ganz verliert und zu widerspruchsvollen Ergebnissen führt, wenn man sich nicht in mystische Theorien verlieren will. Da wir aber einen prinzipiellen Unterschied zwischen menschlicher und tierischer Psyche vom naturwissenschaftlichen Standpunkt aus nicht anerkennen können, so dürfen wir auch bei unserem Problem nicht beim Menschen endgültig haltmachen, wenn wir die Frage philosophisch betrachten, sondern müssen uns aller angedeuteten Folgerungen wenigstens bewußt sein. Den Bewußtseinsbegriff und das Unbewußte philosophisch betrachten heißt eben, ihn in einer Weltanschaunng unterbringen und schließlich müssen wir von allen Begriffen, mit denen wir arbeiten, verlangen, daß sie in unsere Weltanschauung passen, mindestens müssen wir nach diesem Ziel streben und daran arbeiten.

Erkenntnistheoretisch hat der Bewußtseinsbegriff sogar manches mit dem Raum- und Zeitproblem gemeinsam. Ebensowenig nämlich wie einen leeren Raum oder eine leere Zeit können wir uns auch ein leeres, d. h. inhaltloses Bewußtsein denken. In gleicher Weise gibt es für unsere unmittelbare Erfahrung keine Vorstellungen, Gefühle und Strebungen ohne Bewußtseinsqualität, ebenso wie alle Dinge im Raum und in der Zeit sind. Das Unbewußte wird ja, wie gesagt, nur indirekt erschlossen. - Dieser Hinweis soll nur dazu dienen, einen weiteren Begriff von der Schwierigkeit des ganzen Problems zu geben und seine Verwandtschaft mit den schwersten philosophischen Fragen anzudeuten.

Wir haben demnach mit folgendem Tatbestand zu rechnen;

Sehen wir von den gehirnphysiologischen Bedingungen des psychischen Geschehens ab, von denen wir nichts wissen, als daß sie überhaupt 
rorhanden sein müssen, so bleiben für unsere Beobachtung nur die psychischen Phänomene übrig. Direkte Erfahrung haben wir, was diese betrifft, nur von den uns bewußten. Ihre Analyse läßt uns die Inhalte und untrennbar davon das Gefühl der Bewußtheit erkennen. Es ist dies das von Ble uler als un beschreibbar bezeichnete Gefühl, das uns vom Automaten unterscheiden würde. Die psychologische Forschung hat uns die Determiniertheit des psychischen Geschehens erkennen lassen, den assoziativen Zusammenhang der einzelnen Glieder der Gedankenkette. Die häufig zu beobachtenden Lücken in der Kette der uns bewußten Assoziationen lassen uns auf das Vorhandensein weniger oder, einem Teil der Autoren zufolge, gar nicht bewußter Zwischenglieder schließen. Den gleichen Schluß gestattet das Auftauchen von Kenntnissen, die nur als Erinnerung an unbewußt gemachte Wahrnehmungen zu deuten sind. Das gleiche gilt für die auftauchenden Gefühle und Antriebe, deren Ursache uns dunkel bleibt. - Diese zu vermutenden unbewußten psychischen Vorgänge lassen sich nun oft leicht rekonstruieren und sind dann so überzeugend, da $\beta$ der Schluß auf sie geradezu etwas $Z$ wingendes hat und das um so mehr, als die Selbstbeobachtung uns lehrt, daß es schon mehr oder minder lebhaft bewußte psychische Vorgänge für uns gibt. $\mathrm{Ob}$ die Bewußtseinsqualität sich mit den assoziativen Verknüpfungen der Vorstellungen untereinander und mit dem Ich-Komplex, von denen sie für unser Erleben nicht isoliert ist, erschöpft, oder ob noch etwas Psychisches dabei zu ihnen hinzukommt, bleibt hierbei außer acht, da es isoliert nicht beobachtet wird: das Phänomen des bewußten psychischen Geschehens wird von dem Erklärungsversuch ja nicht berührt. Der Begriff der Bewußtseinsqualität im Bleulerschen Sinn für sich allein betrachtet ist somit eine Abstraktion, tatsächlich wird sie ja losgelöst für sich, nicht angetroffen. Auch der Begriff des Unter- oder Unbewußten ist nur eine Abstraktion von Eigenschaften oder vielmehr in minderem Grade vorhandenen oder ganz fehlenden Eigenschaften psychischer Vorgänge, welch letztere wir, soweit es sich um ganz unbewußte handelt, sogar erst indirekt erschließen müssen, also nur vermuten. Wir können uns drehen und winden wie wir wollen, wir bekommen nichts Positives in die Hand.

Diese Abstraktionen tragen nun aber die Merkmale der Vaihingerschen Fiktionen. Wenn wir das Bewußtsein von den psychischen Inhalten trennen, so bedienen wir uns einer fiktiven Größe, ebenso wie bei der Trennung der Schwerkraft von den Phänomen des Falles der Körper, der Pendelbewegung und des Umlaufes der Gestirne. Das Unbewußte hingegen ist die Fiktion, daß es psychisches Geschehen ohne Bewußtseinsqualität gebe.

Wenn nun Vaihinger das "Unbewußte" als die ,greulichste" unter den "schlechten Fiktionen" bezeichnet, so erklärt sich dies 
vielleicht daraus, daß er dies Urteil in dem Kapitel über die Personifikation von Phänomenen fällt und hier unter dem Unbewußten ein personifiziertes Unbewußtes versteht, das auch die Anhänger des Begriffes des Unbewußten, soweit sie hier zitiert sind, wohl zum größten Teil verwerfen würden. Positiv ist nur das Erlebbare, das Phänomen des bewußten psychischen Geschehens. Bleiben wir uns darüber klar, daß wir es tatsächlich nur mit Phänomenen und mit Schlußfolgerungen zu tun haben, die aber feste phänomenale Grundlagen haben müssen, so sind für die Psychologie und Psychopathologie die Begriffe des Bewußtseins und des Unbewußten rechnungsergiebige, also wertvolle Als-Ob-Betrachtungen oder Fiktionen, die wir nicht entbehren können; eine $\mathrm{Hy}$ pothe se aber, wonach faktisch ein Gebiet des Bewußtseins und ein ebensolches des Unbewußten als etwas Selbständiges existierten, wäre oberflächlich und stünde nicht im Einklang mit unseren Beobachtungen und strengen Schlußfolgerungen.

Der Zweck dieser Arbeit wäre erreicht, wenn dadurch die Vaihingersche Als-Ob-Betrachtung Eingang auch in die Erörterungen des Problems vom Bewußtsein und Unbewußten fände.

\section{Literaturverzeichnis.}

1) Vaihinger, Die Philosophie des Als-Ob. Felix Steiner, Leipzig 1918. 2) W u ndt, Sinnliche und übersinnliche Welt. Alfred Kröner, Leipzig. -.- 3) Ziehen, Leitfaden der physiol. Psychologie in 15 Vorlesungen. Gustav Fischer, Jena 1908. - ${ }^{4}$ ) Wundt, Grundriß der Psychologie. XII. Aufl. Alfred Kröner, Leipzig 1914. - 5) Storch, Versuch einer psychophysiol. Darstellung des Bewußtseins, zugleich ein Beitrag zur Lehre von der Funktion der Großhimrinde. Karger, Berlin 1902. $\left.-{ }^{6}\right)$ R uckhaber, Das Denkproblem und seine Lösung, in Neue Weltanschauung, Zeitschr. f. Philos. u. Naturwissenschaften. Bielefeld, 9. Jahrg. 1920, Heft 2. ${ }^{7}$ Ebbinghaus, Abriß der Psychologie. II. Aufl. Veit \& Comp., Leipzig. 8) Bleuler, Lehrbuch der Psychiatrie. 1I. Aufl. Springer, Berlin 1918. 9) Freud, Über Psychoanalyse. Fünf Vorlesungen usw. Franz Deuticke, Lcipzig und Wien 1910. - ${ }^{10}$ ) Hollos, Die Phasen des Bewußtseins. Intcrnat. Zeitschr. f. ärztl. Psychoanal. 5. Jahrg. 1919, Heft 2. - ${ }^{11}$ ) Kretsch mer, Zur Kritik des Unbewußten. Zeitschr. f. d. ges. Neurol. u. Psych. 46, 1919. - ${ }^{12}$ ) Kretsch mer, Seele und Bewußtsein. Kritisches zur Verständigung mit Bleuler. Zeitschr. f. d. ges. Neurol. u. Psych. 53, 1919. - ${ }^{13}$ ) Bleuler, Zur Kritik des Unbewußten. Zeitschr. f. d. ges. Neurol. u. Psych. 53, 1919. — ${ }^{14}$ ) B umke, Über unbewußtes psychisches Geschehen. Zeitschr. f. d. ges. Neurol. u. Psych, 56, 1920. - ${ }^{15}$ ) Lewin, Das Unbewußte und seine Bedeutung für die Psychopathologie. Referat über einen Vortrag in der Berl. Gesellsch. f. Psych. u. Nervenkrankh. Sitzung vom 10. V. 1920. Zeitschr. f. d. ges. Neurol. u. Psych. Referate u. Ergebnisse. 21, 5/6. 1920. - ${ }^{16}$ ) Schweninger, Zur Psychol. d. Besonnenheit. Vortr. auf d. 45. Wanderversammlung südd. Neurol. u. Irrenärzte zu Baden-Baden, V. 1920. Referiert in der Zeitschr. f. d. ges. Neurol u. Psych. Ref. u. Erg. 21, 5/6. 1920. - ${ }^{17}$ ) Lehmann, Zauberei und Aberglaube. Stockholm. - ${ }^{18}$ ) Bleuler, Dementia praecox oder Gruppe der Schizophrenien. Im Handbuch der Psychiatrie von Aschaffenburg. - 19) Hartmann, E. v., Philosophie des Unbewußten Bearbeitet von Wilh. v. Schnehen. Alfred Kröner, Leipz:æ. 